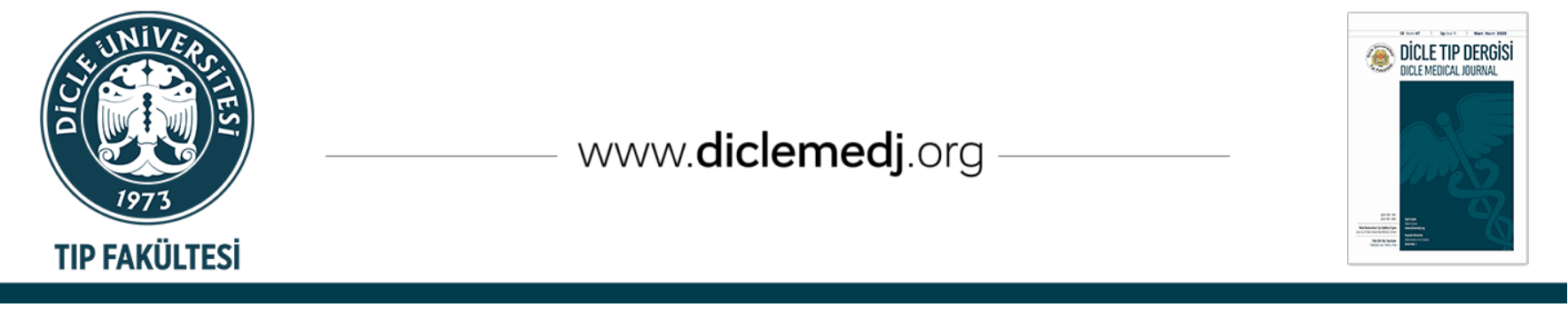

Özgün Araștırma / Original Article

\title{
Lomber Disk Hernisi Cerrahisinde Uygulanan Farklı Anestezi Yöntemlerinin Karşılaştırılması
}

\author{
Erdal Doğan $1 \mathrm{D} 1$ \\ 1 Özel Sultan Hastanesi, Anesteziyoloji ve Reanimasyon AD, Diyarbakır, Türkiye
}

Geliş: 11.03.2020; Revizyon: 30.05.2020; Kabul Tarihi: 06.07.2020

$\ddot{0} \mathbf{z}$

Giriş: Lomber disk hernisi cerrahisi beyin cerrahisi pratiğinde sık yapılan ameliyatlardan biri olup sıklıkla genel anestezi altında yapılmaktadır. Genel anesteziye alternatif yöntem olan spinal anestezi, tüm spinal cerrahi ișlemlerinde uygulanabildiği gibi pek çok avantaja sahiptir. Kliniğimizde lomber disk hernisi cerrahisinde uygulanan farklı anestezi yöntemlerinin etkinliklerini karşılaştırmayı amaçladık.

Yöntemler: Bu çalışma hastane yönetimi onayı alındıktan sonra anesteziyoloji ve reanimasyon kliniğinde yapılmıştır. Kliniğimizde Mart 2017-Temmuz 2019 tarihleri arasında lomber disk hernisi nedeni ile spinal ya da genel anestezi altında elektif olarak opere edilen, ASA I-III, 18-70 yaş arası 234 hasta dosyaları retrospektif olarak incelendi. Hastaların demografik verileri, ameliyat süresileri, ilk mobilizasyon zamanları, efedrin yapılan hasta sayısı, postoperatif deksketorofen tüketimleri, postoperatif tramadol tüketimleri, herniasyon seviyeleri, spinal anestezi blok başarı oranı ve post spinal baş ağrısı gelişen hasta sayısı, hemodinamik parametreleri, operasyon anında ya da sonrasında gelişen komplikasyonlar kaydedildi.

Bulgular: Toplamda 234 hasta çalışmaya dahil edildi. Bu hastalardan 212 tanesi spinal anestezi, 22 tanesi genel anestezi altında ameliyat oldu. 3 hastada post spinal başağrısı gelişti. Postoperatif ilk analjezik ihtiyacı zamanı, total deksketorofen tüketimi, total tramadol tüketimi ve ameliyat süresi spinal anestezi grubunda anlamlı bir şekilde daha düşük bulundu.

Sonuç: Lomber disk cerrahisinde spinal anestezi etkili, güvenli ve iyi bir postoperatif ağrı konforu sağlamakla birlikte, ameliyatın uzun sürmemesinin beklendiği tek seviye herniasyonlarda daha yaygın bir şekilde kullanılabileceği düşüncesindeyiz.

Anahtar kelimeler: Lomber disk hernisi, spinal anestezi, genel anestezi.

DOI: 10.5798/dicletip.800263

Correspondence / Yazışma Adresi: Erdal doğan, Selahaddini eyyübi mah. aydın arslan bulvarıM.T.A. bölge müd. Karşısı Özel Sultan Hastanesi/ Posta kodu: 21080Diyarbakır, Türkiye e-mail: drerdaldogan21@gmail.com 


\title{
Comparison of Different Anesthetic Methods Used in Lumbar Disc Herniation Surgery
}

\begin{abstract}
Objective: Lumbar disc herniation surgery is one of the common surgeries conducted in the brain surgery practice and is often performed under general anesthesia. As an alternative method to general anesthesia, spinal anesthesia can be used in all spinal surgical procedures and has several advantages. We aimed to compare different anesthetic methods used in the lumbar disk herniation surgery in our clinic.

Method: This study was carried out at the anesthesiology and reanimation department after approval of the hospital management. 234 ASA I-III patients between the age of 18 and 70 years who had undergone elective operation under spinal or general anesthesia due to lumbar disc herniation between March 2017 and July 2019 in our clinic were retrospectively examined and included in the study. Patients' demographic data, operative time, the first mobilization times, the number of patients treated with ephedrine, postoperative deksketorofen consumptions, postoperative tramadol consumption, herniation levels, spinal anesthesia block success rate and number of patients developing postspinal headache, hemodynamic parameters, intraoperative or postoperative complications was recorded.
\end{abstract}

Findings: Data of 234 patients were evaluated. 212 of these patients underwent surgery under spinal anesthesia while 22 of them received general anesthesia. Post spinal headache developed in 3 patients. The time to the first postoperative analgesic request,total deksketorofen consumption, total tramadol consumption andsurgery timewere found significantly lower in the spinal anesthesia group.

Conclusion: As well as providing an effective, safe and good postoperative pain comfort in lumbar disk surgery, spinal anesthesia can be more commonly used in single-level herniations for which surgery is not considered to take too long.

Keywords: Lumbar disc hernia, spinal anesthesia, general anesthesia.

\section{GíRiş}

Bel ağrısı toplumdaki bireylerin bește dördünde yaşamlarının herhangi bir döneminde kendini hissettirmektedir. Bel ağrısının en sık nedenlerinden bir tanesi lomber disk hernisi (LDH)olup intervertebral diskin spinal kanala herniasyonu sonucu oluşur. LDH ağır motor kayıp meydana getirmesi durumunda ve 3-4 hafta içerisinde geçmeyen şiddetli siyataljiye neden olursa cerrahi müdahele önerilmektedir ${ }^{1}$.

Lomber disk cerrahisi en yaygin omurga işlemlerinden biri olup çoğunlukla genel anestezi altında yapılmaktadır ${ }^{2}$. Genel anestezi, ameliyat için verilen pozisyona bağlı gelişebilecek komplikasyonlarda havayolunun güvende olması ve cerrahinin uzaması durumlarında avantaj gibi görülmektedir. Prone pozisyonunda yapılan bu ameliyatlarda, genel anestezi altında dolaşım problemleri, eklem ve sinir hasarlarl, endotrakeal entübasyon, ekstübasyon ve derlenme dönemlerinde bir çok komplikasyon meydana gelebilmektedir. Bunun aksine spinal anestezide özellikle postoperatif solunum problemleri, analjezik ihtiyacı azalır ve derin ven trombozu insidansı azalmakla birlikte, buna yönelik yayınlara olan ilgi artmaktadır ${ }^{3}$.

\section{YÖNTEMLER}

$\mathrm{Bu}$ çalışma hastane yönetimi onayı (tarih:18.10.2019/sayı:44) alındıktan sonra anesteziyoloji ve reanimasyon kliniğinde yapılmıştır. Kliniğimizde işlemleri aynı anestezi uzmanı tarafından yapılan, Mart 2017-Temmuz 2019 tarihleri arasında, LDH nedeni ile spinal ya da genel anestezi altında elektif olarak opere edilen, ASA I-III, 18-70 yaş arası 234 hastanın dosyası retrospektif olarak incelendi.

Tüm hastalara işlem öncesinde $20 \mathrm{G}$ branül ile damar yolu açıldığı, ameliyat masasına alınan hastalara standart monitörizasyon olarak; elektrokardiyogram, pulse oksimetre ve noninvaziv kan basıncı ölçümü uygulandı̆̆ görüldü. Spinal anestezi ile opere olan hastalara 
oturma veya yan uzanma pozisyonda, L3-4 aralığından standart olarak tüm hastalara 27 G kalem uçlu spinal iğne ile $15 \mathrm{mg}$ intratekal hiperbarik bupivakain yapıldığı tespit edildi. Yeterli blok seviyesi T10 olduktan sonra bu seviyenin kayıt altına alındığı ve cerrahi pozisyonu olan prone pozisyonuna hastaların alındığı görüldü. Hastalarda anksiyete varlığında $\quad 0.02-0.04 \mathrm{mg} / \mathrm{kg}$ i.v. midazolam uygulandığı, ağrı varlığında $1-2 \mathrm{mcg} / \mathrm{kg}$ i.v. fentanil yapıldığı dosya kayıtlardan anlaşıldı. Genel anesteziyi tercih eden hastalara ya da yeterli duyusal ve motor blok gelişmeyen hastalarda genel anestezi uygulandığı anlaşıldı. Genel anestezi ile opere olanlarda; 0.03-0.04 $\mathrm{mg} / \mathrm{kg}$ i.v. midazolam, $2 \mathrm{mcg} / \mathrm{kg}$ i.v. fentanil ve 2-3 mg/kg i.v. propofol ile anestezi indüksiyonu yapıldığı görüldü. Kas gevşetici ajan olarak 0,6 $\mathrm{mg} / \mathrm{kg}$ i.v. roküronyum sonrası endotrakeal entübasyon yapıldığı ve anestezi idamesinin \%2 sevofluran ile sağlandığı dosya kayıtlarından ve hastane otomasyon verilerinden anlaşıldı. Operasyon bitiminde hastalar derlenme odasına alındı. Spinal anestezi yapılan grupta, spinal blok seviyesi T10 ve altında olan hastalar ile genel anestezi yapılan grupta Modifiye Aldrete Derlenme Skor'laması 9 ve üzerinde olanhastalarkliniğe transfer edildi.

Hastalar, verilen anestezi şekline göre spinal anestezi grubu (Grup: S), genel anestezi grubu (Grup: G) olmak üzere 2 gruba ayrıldı. Hastaların demografik verileri, ameliyat süresi, postoperatif ilk analjezik ihtiyacı zamanları, postoperatif deksketorofen tüketimi, postoperatif tramadol tüketimleri, herniasyon seviyeleri, spinal anestezi grubunda blok başarı oranları ve postspinal baş ağrısı gelişen hasta sayısı, hemodinamik parametreleri, operasyon anında ya da sonrasında gelişen komplikasyonlar hasta dosyaları ve hastane otomasyon sisteminden taranarak kaydedildi.

\section{İstatistiksel Analiz}

Analiz için IBM SPSS 22 paket programından yararlanılmış, iki bağımsız grup arasında istatistiksel olarak anlaml bir fark olup olmadığ Mann-Whitney $U$ testi ile incelenmiştir. Değişkenler arasındaki ilişki durumu $X^{\wedge} 2$ (Ki kare) testiyle araştırılmış ve ilişkili olduğu görülen değişkenler arasındaki ilişkinin gücü Eta ve Cramer's V katsayıları kullanılarak ortaya konmuştur. $\mathrm{p}<0.05$ anlamlı kabul edilmiştir.

\section{BULGULAR}

Çalışmamızda toplam 234 hastanın verileri değerlendirildi. Hastalardan 212 tanesi spinal anestezi, 22 tanesi genel anestezi altında ameliyat oldu (Tablo I: Demografik veriler).

Tablo I: Demografik veriler

\begin{tabular}{|c|c|c|c|}
\hline \multicolumn{4}{|l|}{ Demografik veriler } \\
\hline & Grup S & Grup G & $\mathbf{p}$ \\
\hline Yaş/yıl & $48.5 \pm 12.7$ & $47.9 \pm 13.1$ & $>0.05$ \\
\hline Kadın/Erkek & $112 / 100$ & $8 / 14$ & $>0.05$ \\
\hline ASA I/II/III & $148 / 43 / 21$ & $16 / 6 / 0$ & $>0.05$ \\
\hline $\begin{array}{l}\text { Herniasyon seviyesi } \\
\text { L3-L4 }\end{array}$ & $10(\% 4,7)$ & $2(\% 9,09)$ & \\
\hline $\begin{array}{l}\text { Herniasyon seviyesi } \\
\text { L4-L5 }\end{array}$ & $120(\% 56,6)$ & $11(\% 50)$ & \\
\hline $\begin{array}{l}\text { Herniasyon seviyesi } \\
\text { L5-S1 }\end{array}$ & $82(\% 38,6)$ & $9(\% 40,9)$ & \\
\hline
\end{tabular}

Anestezi türü ile ameliyat süresi arasında anlamlı ilişkinin olduğu tespit edildi ( $p$-değeri $<0.05$,p-değeri=0.000). Bu ilişkinin gücü ile ilgili yorum yapabilmek için

Eta katsayısından yararlanılmış ve 0.77 olarak hesaplandı. Bu sonuçlara dayanarak, anestezi türü ile ameliyat süresi arasında güçlü bir ilişkinin olduğu sonucuna varıldı.

Ameliyat süresi bakımından spinal anestezi ile genel anestezi arasında anlamlı fark olup olmadığı Mann-Whitney U testi ile araştırıldı. \%95 güven düzeyinde spinal ile genel anestezi arasında istatistiksel olarak anlamlı farklılığın olduğu görüldü (p-değeri <0.05, pdeğeri=0.000). 
İlk mobilizasyon zamanı, postop ilk analjezik ihtiyacı zamanı, ameliyatta uygulanan anestezi yöntemi ile kullanılan deksketoprofen miktarı arasındaki ilişki, ameliyatta uygulanan anestezi yöntemi ile kullanılan tramadol miktarı arasındaki ilişki parametreleri; spinal anestezi ile genel anestezi arasinda istatistiksel olarak anlamlı fark olup olmadığı Mann-Whitney U testi ile araştırıldı.

İlk mobilizasyon zamanı bakımından spinal anestezi ile genel anestezi arasında istatistiksel olarak anlamlı fark olmadığı tespit edildi. (Tablo II: Klinik veriler).

Tablo II: Klinik veriler

\begin{tabular}{|c|c|c|c|}
\hline \multicolumn{4}{|l|}{ Klinik Veriler } \\
\hline & Ip S & Ip G & $\mathbf{p}$ \\
\hline Postop ilk analjezik ihtiyacı/dk & 453.65 & 21,81 & $<0.05$ \\
\hline İlk mobilizasyon zamanı / dk & 362.24 & 347,36 & $>0.05$ \\
\hline Deksketorofen tüketimi / mg & 56.60 & 70,45 & $<0.05$ \\
\hline Tramadol yapılan hasta \% & $\% 3,8$ & $\% 59.1$ & $<0.05$ \\
\hline Ameliyat süresi /dk & $41.9 \pm 5.6$ & $64.5 \pm 3.7$ & $<0.05$ \\
\hline Efedrin yapılan hasta \% & $\% 12,4$ & $\% 0$ & $>0.05$ \\
\hline $\begin{array}{l}\text { Ortalama arteryel basınç } \\
(\mathrm{mm} / \mathrm{hg})\end{array}$ & & & \\
\hline Preop & 92 & 94 & $>0.05$ \\
\hline 5. $\mathrm{dk}$ & 87 & 91 & $>0.05$ \\
\hline 15. $\mathrm{dk}$ & 69 & 84 & $<0.05$ \\
\hline 30. $\mathrm{dk}$ & 79 & 80 & $>0.05$ \\
\hline 60. dk & 75 & 82 & $>0.05$ \\
\hline 90. $\mathrm{dk}$ & 82 & 84 & $>0.05$ \\
\hline Postop & 79 & 98 & $<0.05$ \\
\hline $\begin{array}{l}\text { Ortalama } \\
\text { sayısı(atım/dk) }\end{array}$ & & & \\
\hline Preop & 84 & 86 & $>0.05$ \\
\hline 5. $\mathrm{dk}$ & 82 & 83 & $>0.05$ \\
\hline 15. $\mathrm{dk}$ & 67 & 82 & $<0.05$ \\
\hline 30. $\mathrm{dk}$ & 75 & 78 & $>0.05$ \\
\hline 60. $\mathrm{dk}$ & 77 & 79 & $>0.05$ \\
\hline 90. $\mathrm{dk}$ & 80 & 83 & $>0.05$ \\
\hline Postop & 76 & 95 & $<0.05$ \\
\hline
\end{tabular}

Postop ilk analjezik ihtiyacı zamanı bakımından spinal anestezi ile genel anestezi arasında istatistiksel olarak anlamlı fark olduğu tespit edildi. Genel anestezi uygulanan hastalarda bu ihtiyaç ortalama 21.81 dakikada meydana gelirken spinal anestezi uygulananlarda ortalama 453.65 dakikada analjeziklere ihtiyaç duyuldu. Ameliyatta uygulanan anestezi yöntemi ile kullanılan deksketoprofen miktarı arasında anlamlı ilişkinin olduğu tespit edildi (p-değeri<0.05, p-değeri=0.001).Kullanılan deksketoprofen miktarı bakımından spinal anestezi ile genel anestezi arasında anlamlı fark olup olmadığı \%95 güven düzeyinde spinal ile genel anestezi arasında istatistiksel olarak anlamlı farklılığın olduğu tespit edildi ( $\mathrm{p}$-değeri $<0.05$, p-değeri=0.001).

Ameliyatta uygulanan anestezi yöntemi ile kullanılan tramadol miktarı arasında anlamlı ilişkinin olduğu görüldü ( $p$-değeri<0.05, pdeğeri=0.000). Kullanılan tramadol miktarı bakımından spinal anestezi ile genel anestezi arasında istatistiksel olarak anlamlı farklılığın olduğu tespit edildi (p-değeri<0.05, pdeğeri=0.000).

Efedrin, spinal anestezi grubunda 29 hastaya uygulandı. Operasyonda kullanılan anestezi yöntemi ile efedrin kullanımı arasında anlamlı ilişki söz konusu olmadığı gözlendi (pdeğeri>0.05, p-değeri=0.064).

Spinal anestezi grubunda $3(\% 1,4)$ hastada post spinal baş ağrısı geliştiği görüldü.

\section{TARTIŞMA}

Çalışmamızda lomber disk cerrahisinde uygulanan spinal anestezi ve genel anestezinin hemodinamik stabilite olarak birbirine benzer olduğunu, spinal anestezi grubunda ameliyat süresinin daha kısa olduğu, postoperatif dönemde daha az analjezik tüketimi, daha az tramadol tüketimi, post operatif ilk 24 saatlik takipte özellikle ağrı yönünden konforlu olduğunu gördük. 
McLain ve ark. yaptıkları çalışmada spinal anestezinin, sinırlı bel cerrahisi geçiren hastalarda genel anesteziye karşı güvenli ve oldukça tatmin edici bir alternatif olduğunu belirtmişlerdir ${ }^{4}$. Spinal anestezi genel anestezi ile karşılaştırıldığında; ameliyat sonrası derlenme döneminin daha konforlu olması, daha az ağrı nedeniyle analjezik ihtiyacın daha az olması, bulantı ve kusma görülme sıklığının daha düşük olması gibi avantajlara sahiptir. Ayrıca spinal anestezinin periferik venöz basıncı düşürmesi sonucu kan kaybı azalır ve cerrahi alana venöz dönüşü azaltmasına bağlı olarak daha iyi bir cerrahi görüş alanı sağlamaktadır. Lomber disk cerrahisi prone pozisyonunda yapıldığı için bilinci açık olan hasta kendisini brakiyal pleksus, ulnar sinir hasarı ve yüzde basınç nekrozu gibi pozisyon kaynaklı komplikasyonlardan korur ${ }^{5}$. Mevcut çalışmalarda ağrı skorunun spinal anestezi sonrasında daha düşük bulunduğu tespit edilmiştir6,7,8. McLain ve ark. yaptıkları çalışmalarda postoperatif ağrı ve bulantı kusmanın spinal anestezi verilen hastalarda daha düşük olduğu sonucuna varmışlardır9. Spinal anestezide nosiseptif yolakların inhibe olması ve sensoryal bloğun motor bloktan sonra ortadan kalkması bu duruma neden olur ${ }^{10}$. Çalışmamızın başlıca kısıtlılığı retrospektif olduğu için hastaların ağrı skorlarını, hasta ve cerrah memnuniyetini belirleyemedik. Spinal anestezi grubunda ilk analjezik ihtiyaç zamanı genel anestezi grubu ile karşılaştırıldığında anlamlı derecede daha uzun bulduk. Yukarıdaki çalışmalara paralel olarak çalışmamızda cerrahi sonrası ilk 24 saatte kullanılan total deksketorofen dozu ve total tramadol dozu spinal anestezi grubunda anlaml derecede daha az bulundu. Spinal anestezi grubunda analjezik ilaçların daha az kullanılmış olması hastaların postoperatif dönemlerini genel anestezi grubuna göre ağrı yönünden daha konforlu geçirdiğini düşünmekteyiz.
McLain ve ark. ameliyat süresini karşılaştırdıkları çalışmalarında, spinal anestezi grubunda ameliyat süresinin daha kısa olduğunu bildirmişler ${ }^{9}$. Biz de çalışmamızda McLain ve ark.'nın buldukları sonuçlara paralel olarak ameliyat süresini spinal anestezi grubunda anlamlı derecede daha kisa bulduk. Bütün ameliyatlar aynı cerrah tarafından yapıldığından ameliyat süresini belirleyen en önemli etken hastalara uygulanan anestezi yöntemidir. Spinal anestezi grubunda; hasta uyanık olduğu için cerrahi pozisyon verilmesine yardımcı olması, genel anestezi indüksiyonu ve anesteziden uyandırma işlemleri olmadığı için ameliyat süresi genel anestezi grubundan daha kısa bulundu. Spinal anestezi yapılan hastalarda ameliyat süresinin kısa olması ameliyat odasının daha efektif kullanılmasına olanak sağladığını düşünmekteyiz.

Tetzlaf ve ark. spinal anestezi ile genel anesteziyi karşılaştırıldıkları çalışmalarında, spinal anestezinin kan basıncinda ve kalp hızında daha fazla düşüşe neden olduğunu bulmuşlardır ${ }^{11}$. Jellish ve ark. çalışmalarında spinal anestezi verilen hastaları genel anestezi verilen hastalarla karşılaştırdıklarında kan basıncının ve kalp hızının daha düşük olduğunu bulmuşlardır ${ }^{5}$. Çalışmamızda spinal anestezi grubunda, 15.dk'da kalp atım hızı ve ortalama arter basincı anlaml olarak genel anestezi grubundan daha düşük bulundu. Efedrin spinal anestezi grubunda 29 hastada kullanılmasına rağmen gruplar arasında anlamlı fark olmadığ tespit edildi. Post op derlenme odasında genel anestezi grubunda kalp atım hızı ve ortalama arter basincl, spinal anestezi grubu ile karşılaştırıldığında anlamlı derecede yüksek bulundu. Ancak diğer zamanlarda kalp hızı ve ortalama arteryel basınç takiplerinde iki grup arasında anlamlı fark bulunmadı.

Literatürlerde kalem uçlu ya da küçük çaplı iğnelerin post spinal baş ağrısının (PSBA) görülme sıklığını düşürdüğünü gösteren pek çok yayın mevcuttur ${ }^{12,13}$. Farklı yayınlarda 
PSBA'nın 22 gauge iğne ile $\% 40,25$ gauge iğne ile $\% 25^{14,15,16}$ gauge iğne ile $\% 2-12$ ve 29 gauge iğne ile \%2'den daha az görülme sıklığına neden olduğu bildirilmiștir15,16,17. McLain ve ark.'nın yaptığı çalışmada spinal ve genel anestezi altında LDH cerrahisi yapılan her iki grupta nöral yaralanma olmadığı ve spinal anestezi alan hastalarda spinal baş ağrısı insidansı \%1,5 bulunduğu bildirilmiştir ${ }^{9}$. Kliniğimizde 27 gauge kalem uçlu spinal iğne kullanılmaktadır, spinal anestezi grubunda $3(\% 1,4)$ hastada post spinal baş ağrısı görülmüştür. Post spinal baş ağrısı, sıvı replasmanı ve analjezikler ile tedavi edilmiş olup hiç bir hastaya epidural kan yaması yapılmasına gerek kalmamıştır. Çalışmamızda hiçbir hastamızda nöronal hasar gelişmemiştir. Spinal anestezi grubunda sadece 2 hastamıza duyusal blok yeterli cerrahiyi sağlayacak seviyeye ulaşmadığı ve motor blok gelişmediği için genel anestezi verildi.

Spinal anestezi altında lomber disk hernisi nedeni ile opere olacak hastalar yeterince bilgilendirilmeli, spinal anestezi sonrası tam motor blok gelişmeden pozisyon verilmemeli ve anksiyetesi olan hastalar sedatize edildikten sonra pozisyon verilmelidir. Hastalara cerrahi pozisyon verildikten sonra sedasyon yapmak havayolu güvenliğini sağlamada zorluk nedeni ile önerilmemektedir.

\section{SONUÇ}

Spinal anestezi ile opere olan hastalar uyanık oldukları için cerrahi pozisyon kolay verilebildiği gibi yüzüstü pozisyonda karşılaşılabilen sinir hasarı, basıya bağlı komplikasyonlardan hastalar nispeten korunabilmektedir. Lomber disk cerrahisinde spinal anestezi etkili, güvenli ve iyi bir postoperatif ağrı konforu sağlamakla birlikte, uyumlu olan hastalarda ve ameliyatın uzun sürmemesinin beklendiği tek seviye herniasyonlarda daha yaygın bir şekilde kullanılabileceği düşüncesindeyiz.
Etik Kurul Kararı: Bu çalışma hastane yönetimi 18.10.2019 tarih ve 44 sayı numarası ile onay alınmıştır.

Çıkar Çatışması Beyanı: Yazarlar çıkar çatışması olmadığını bildirmişlerdir.

Finansal Destek: Bu çalışma her hangi bir fon tarafından desteklenmemiştir.

Declaration of Conflicting Interests: The authors declare that they have no conflict of interest.

Financial Disclosure: No financial support was received.

\section{KAYNAKLAR}

1. Spencer D.L, Bernstein A.J. Lumbar intervertebral disc surgery. Spinal Surgery (ed.K.H Bridwell and R.L. DeWald). Lippincott-Raven Publishers:Philadelphia.1547-61.

2. Nicassio N, Bobicchio P, Umari M, et all. Lumbar microdiscectomy under epidural anaesthesia with the patient in the sitting position: a prospective study. Journal of Clinical Neuroscience . 2010;17:1537-40.

3. Rodgers A, Walker N, Schug S, et all. Reduction of postoperative mortality and morbidity with epidural or spinal anaesthesia: results from overview of randomised trials. BMJ. 2000;321: 1493-505.

4. McLain RF, Tetzlaff JE, Bell GR, et all. Microdiscectomy: Spinal anesthesia offers optimal results in general patient population. JSOA. 2007;16:5-11.

5. Jellish WS, Thalji Z, Stevenson K, et all. A prospective randomized study comparing shortand intermediate-term perioperative outcome variables after spinal or general anesthesia for lumbar disc and laminectomy surgery.Anesth Analgesia. 1996;83:559-64.

6. McLain, Robert F, Marcia AP. Stres response and optimization of perioperative care. Disease A Month. 2003;49:9-14.

7. Becq MC, Verdin M, Riegel B, et all. Effects hemodynamiques de la position genupectorale au cours de la chirurgie de la hernie discale lombaire: 
rachianesthesie vs anaesthesia generale. Agressologie. 1993;34:49-50.

8. Hassi N, Badaoui R, Cagny BA, et all. Spinal anesthesia for disc herniations and lumbar laminectomy. Cah Anesthesiol. 1995;43:21-5.

9. McLain RF, Kalfas I, Bell GR, et all. Comparison of spinal and general anesthesia in lumbar laminectomy surgery: a case-controlled analysis of 400 patients. J Neurosurg Spine. 2005; 2:17-22.

10. Covino BG. Rationale for spinal anesthesia. International Anesthesiology Clinics. 1989;27:8-12.

11. Tetzlaff JE, Dilger JA, Kodsy M, et all. Spinal anaeshesia for elective lumbar spine surgery. Journal of Clinical Anesthesia.1998; 10:666-9.

12. Lambert DH, Hurley RJ, Hertwig L, et all. Role of needle gauge and tip configuration in the production of lumbar puncture headache. Reg Anesth.1997; 22: 66-72.
13. Ready LB, Cuplin S, Haschke RH, Nessly M. Spinal needle determinants of rate of transdural fluid lake. Anaesth Analg.1989;69:457-60.

14. Üniver S, Özgök A, Ebil S. 24 G Sprotte ve 26 G Atracuan spinal iğnelerin elektron mikroskopik ve postdural ponksiyon baş ağrısı yönünden karşılaştırılması. Anestezi Dergisi. 1998;6:83-6.

15. Barker P. Headache after dural puncture. Anesthesia.1989;44:696-7.

16. Geurts JW, Haanschoten MC, Van Wijk RM, et all. Post-dural puncture headache in young patients. A comparative study beween use of $0.52 \mathrm{~mm}$ (25gauge) and $0.33 \mathrm{~mm}$ (29-gauge) spinal needles. Acta Anesth Scand. 1990; 34: 350-3.

17. Flaatten H, Rodt SA, Vamnes J, et all. Postdural puncture headache. A comparison between 26- and 29- gauge needles in young patients. Anaesthesia.1989; 44: 147-9. 